\title{
Changing trends in adolescent alcohol use among Czech school-aged children from 1994 to 2014
}

\author{
Ladislav Kážmér, ${ }^{1,2}$ Ladislav Csémy ${ }^{1}$ \\ ${ }^{1}$ National Institute of Mental Health, Klecany, ${ }^{2}$ Department of Social Geography and \\ Regional Development, Faculty of Science, Charles University, Prague, Czech Republic
}

Significance for public health

Substance use during the period of adolescence is one of the most significant priorities of the public health agenda. The study provides with a unique 20 -year time series of data on adolescent alcohol use since the establishment of the Czech Republic in the early 1990s. Detailed analysis stratified by genders and specific age-groups of adolescents is conducted. The analysis confirmed significant changes in adolescent alcohol use. After a long period of continuous increase, which was present particularly among girls, a sharp drop across genders and all age-groups was recorded. The drop is in contrast with a steady and continuous decline recorded in most of the countries of Western Europe and North America. The specific factors and institutional settings present in Czechia are discussed.

\begin{abstract}
Background: For an efficient planning of public health policy, the regular monitoring over health-related behaviors among vulnerable population groups is necessary. The aim of this study is to examine the temporal trends in alcohol use among the Czech adolescent population.

Design and methods: Data from the Health Behaviour in Schoolaged Children (HBSC) project conducted in Czechia from 1994 to 2014 were used. Adolescent alcohol use was assessed via two indicators: i) weekly alcohol use (beer, wine, and/or spirit), ii) repeated lifetime drunkenness (having been drunk on two or more occasions in life). Trends in alcohol use were modelled separately for boys and girls. Binary logistic regression was conducted with survey period as an independent predictor of the alcohol indicator.

Results: There were significant changes in adolescent alcohol use since 1994. Between 1994 and 2010, there was a gradual upward in the prevalence. However, in the recent period of 2014, an unprecedented drop in alcohol use was recorded.

Conclusions: Despite the significant drop in the prevalence of alcohol use among the Czech youth in recent years, alcohol drinking in adolescence remains an important challenge for the national health policy. Further research will show whether these changes in adolescent health-related behavior are of a temporary or a permanent nature.
\end{abstract}

\section{Introduction}

Alcohol is the most widely used psychoactive substance in the developed world, responsible for a significant portion of avoidable morbidity and mortality in Europe, as well as for social inequalities in health in general. ${ }^{1-3}$ Adverse health effects of alcohol use include a higher risk for emergence of a range of chronic diseases, including diseases of the digestive system, cardiovascular and cerebrovascular diseases, several sites of cancer, mental and behavioral disorders, and external causes of morbidity and mortality. The acute alcohol-related risks comprise alcohol poisoning, fatigue, reduced immunity and proneness to infectious diseases, unintended injuries, as well as aggressive behavior and victimization. As documented by the international research conducted by WHO, in the European Union, alcohol consumption is the third most important risk factor for ill health and premature death. ${ }^{4}$

Alcohol-related risks are of a cumulative nature. The lower the age of initiation with alcohol use, and the higher the overall volume consumed within an individual's lifespan, the higher the risks of alcohol-induced ill health, as well as risks of transition from a regular drinking patterns into harmful alcohol use and possible dependence at a later age. Given this cumulativeness and specific vulnerability of an adolescent population to alcohol use, both regular monitoring of underage drinking and implementation of preventative measures are of the most significant priorities of public health policy in European countries.

Among the Czech adult population, alcohol consumption is high with a relatively steady trend since the establishment of the Czech Republic in the early 1990s. ${ }^{2,5}$ As the young generation adopts norms, values and attitudes - including health-related patterns of behavior - not only from their parents, but also from the society as a whole, ${ }^{6}$ the importance of monitoring the prevalence of alcohol use among Czech adolescents should be highlighted even more.

There are several approaches to measure substance use prevalence in a specific study group. The approaches range from objective measures of alcohol biomarkers, conducted by an expertized staff and examined in a controlled study environment, to selfreported measurements, relying on participants' memory, selfreflexion and willingness to answer truthfully. The latter approach is typically applied in large-sample surveys, where the objective measurement would be costly or complicated to obtain. Due to the specific status of the adolescent population, and relative ease of self-reported measurement acquisition, the latter approach is favored in adolescent substance use prevalence surveys, applied within large-sample school-targeted research designs worldwide; e.g. in studies like Monitoring the Future in the United States, ${ }^{7}$ ESPAD in Europe, ${ }^{8}$ ASSAD in Australia, ${ }^{9}$ etc. Despite its selfreported nature, the approach is considered as a good indicator of adolescent risk behaviors, including measurement of adolescent alcohol use. ${ }^{10-12}$

Since the early 2000s, a continuous decline in alcohol use among adolescents from the Western European and Scandinavian countries was recorded. ${ }^{8,13,14}$ Similar trends were documented in the US, ${ }^{7,15}$ Canada $^{16}$ and Australia, ${ }^{9,17}$ as well. However, the widespread decrease was not equally present in all countries of the Central and Eastern Europe. ${ }^{14}$ In Czechia, a continuous increase in adolescent alcohol use between 1995 and 2011 was documented, 
with no signs for decline. ${ }^{18}$ This increasing trend was apparent particularly among the Czech adolescent girls. ${ }^{19}$

Surprisingly, the results of the recent international European School Survey Project on Alcohol and Other Drugs (ESPAD), conducted with European adolescents in 2015, pointed to the significant general decrease in both alcohol and tobacco use also among the adolescents from the Central and Eastern European countries, including Czechia. ${ }^{8,20}$ For example, the prevalence of last month alcohol intoxication among the adolescent Czechs unexpectedly dropped from $21.3 \%$ on $14.7 \%$, the last month binge drinking ( 5 or more drinks of alcohol during one occasion) from $54.0 \%$ on $41.9 \% .{ }^{18}$ Those new trends in adolescent substance use took a significant interest of the Czech public health professionals, which led to an intensive scientific debate on the topic. ${ }^{21}$

Given the unexpected changes in the prevalence of substance use among adolescent Czechs documented by the recent ESPAD project, in this study, we aim to analyze the temporal trends based on the data provided by another survey aimed at adolescent population - the Health Behaviour in School-aged Children. The data cover time period overlapping with the one provided by the ESPAD. As alcohol use is generally more prevalent among older adolescents, the analyses are conducted separately for both different age groups and genders. This brings a deeper insight into the phenomenon, as compared to that provided by the ESPAD, where only one age-specific group is available.

To large extent, the results of both the ESPAD and HBSC studies are congruent. After a long period of continuous and steady increase in alcohol use, a significant drop among the adolescent Czechs was confirmed. The drop was apparent across both genders and all the age groups, pointing to the significant changes in health-related behaviors among the contemporary Czech youth.

\section{Design and methods}

Nationally representative data from the series of cross-sectional surveys, conducted in the Czech Republic, focusing on adolescent health conditions were applied, surveyed within the international project of Health Behaviour in School-aged Children (HBSC). Since the Czech Republic has been participant of the HBSC consortium since 1994, all the data available until the recent HBSC survey in 2014 were used.

As regards the level of alcohol use, two sets of questions were available within the Czech HBSC dataset, fully comparable between the survey periods. The first set of questions asked on the frequency of use of three types of alcoholic beverages - beer, wine, and spirits. The questions were formulated as follows: "At present, how often do you drink anything alcoholic, such as beer, wine or spirits?" with answer categories " 1 = never", " 2 = rarely", " $3=$ every month", "4 = every week", and " 5 = every day". From this set of questions, we derived a dichotomized variable as a first indicator of adolescent alcohol use called "weekly alcohol use", where $1=$ use of any alcoholic beverage weekly or daily, $0=$ otherwise. The second question was about the frequency of lifetime drunkenness: "Have you ever had so much alcohol that you were really drunk?" The answers regarding being drunk two times or more often were coded as cases of repeated lifetime drunkenness. To simplify, this indicator is in the text referred briefly as "repeated drunkenness".

Both sets of questions were asked to 11-, 13- and 15-year old student respondents. Questions were collected through self-completion questionnaires, together with a range of other health-related indicators, administered in the classroom. In all HBSC surveys, student's participation was voluntary. Therefore, no special approval or parental permission was required for the study.

The analysis was conducted in several steps. In the first step, gender- and age-specific prevalence estimates of alcohol use with the corresponding $95 \%$ confidence intervals were calculated for both sets of questions (weekly alcohol use; repeated drunkenness). These were calculated for each survey period between 1994 and 2014. In order to visually assess the temporal trends in adolescent alcohol use, prevalence estimates for the both sets of questions were plotted to graphs separately for boys and girls.

The graphs revealed two substantial characteristics of trends in alcohol use, important for the next step of analyses: a) there was an increasing trend in both alcohol indicators between 1994 and 2010; b) however, in 2014, a significant drop was recorded.

In the last step of analyses, we were interested in both a) to make some generalizations of temporal trends of adolescent alcohol use, and $b$ ) to test for statistical significance of trends through the regression modelling approach. As the graphical visualization of data revealed a significant breakthrough between 2010 and 2014, we decided to split the regression analysis into separate models for two consecutive time periods: 1994-2010 and 2010-2014. Hence, we conducted a series of logistic regression models with a survey period as a predictor of two respective alcohol indicators used in the study (weekly alcohol use; repeated drunkenness).

The regression models were defined as follows:

A) Model for 1994-2010:

$\log [\pi /(1-\pi)]=$ Constant $+\beta^{*}($ Period $)$, Period $\in\{0,4,8,12,16\} ;$

B) Model for 2010-2014:

$\log [\pi /(1-\pi)]=$ Constant $+\beta^{*}($ Period 2014$)$, Period $2014 \in$ $\{\mathrm{No}=0, \mathrm{Yes}=1\}$

where $\pi$ states for the prevalence (\%) of adolescent alcohol users, resp. student drunkenness. In model A, Period is a number of years since the first HBSC survey in 1994. In model B, Period 2014 is a binary variable testing for decline in alcohol consumption between 2010 and 2014.

We stated that questions on alcohol were asked to 11-, 13- and 15-year-old respondents. However, as the level of alcohol use was very low among the 11-year olds, we decided to conduct both graphical assessment and regression analyses only among 13- and 15-year-old students, and to keep prevalence rates computed for the 11-year olds only for illustrative purposes.

\section{Results}

Table 1 provides with the description of the dataset compiled from the last six HBSC surveys conducted in the Czech Republic from 1994 to 2014. Data are presented separately by the gender and age of respondents. Number of participants varied between 3585 in 1994 and 5055 in 2014, with a proportional share of boys and girls, as well as all three age groups (the 11-, 13- and 15-year olds) surveyed in each HBSC study. Summing up through all the six HBSC survey periods, the total sample size used in our study was 26589 student respondents (13021 boys and 13568 girls).

Table 2 summarizes age- and gender-specific prevalence estimates of adolescent alcohol use from 1994 to 2014, computed for two indicators - weekly alcohol use and repeated drunkenness. Comparing the prevalence rates between age groups it is apparent, how the proportion of students consuming alcohol increases with their age. For example, in 2010, 6.2\% of the 11-year-old Czechs declared weekly alcohol use. However, among the 13-year olds, the proportion was 2.5-times higher (15.9\%) and among the 15- 
year olds it was almost 6-times (36.4\%) higher. Regarding the repeated drunkenness in 2010 , differences between age groups were pronounced even more (2.9\% among the 11 -year olds, $15.3 \%$ among the 13 -year olds, and $43.0 \%$ among the 15 -year olds).

Comparing prevalence estimates between the genders, boys had generally higher rates of alcohol use than girls in both indicators during the whole period 1994-2014. However, these inequalities were more pronounced at the beginning of the study period. Later, the relative differences between genders gradually reduced with rather converging prevalence rates in both alcohol indicators. For example, the proportion of 15-year-old students declaring weekly alcohol use was twofold higher among boys than girls in 1994 (38.3\% vs. 18.5\%). In 2010, this relative difference reduced on $1.4(42.2 \%$ vs. $30.8 \%)$.

In the next step of analysis, temporal trends in alcohol use were plotted to graphs. Figures 1 and 2 show temporal changes in both alcohol indicators among 13- and 15-year-old students during 1994 and 2014, separately by gender. The corresponding $95 \%$ con- fidence intervals of prevalence estimates are also plotted.

From both Figures 1 and 2 it is apparent that adolescent alcohol use had been gradually increasing by the year 2010, particularly among girls. For example, among 15-year-old students, the prevalence of repeated drunkenness between 1994 and 2010 increased twice among girls (from $19.2 \%$ to $39.6 \%$ ) and 1.3-times among boys (from $35.5 \%$ to $46.4 \%$ ). However, in 2014 there was a significant drop in alcohol use, recorded by both alcohol indicators used in the analysis. This was present among both boys and girls and all the age groups surveyed within the HBSC project. For example, the prevalence of weekly alcohol use among 15-year olds decreased by index 0.37 among girls (from $30.8 \%$ in 2010 to $11.3 \%$ in 2014 ) and by index of 0.45 among boys (from $42.2 \%$ in 2010 to $18.8 \%$ in 2014).

Finally, temporal trends in alcohol use were tested by logistic regression models. The binary indicators of both weekly alcohol use and repeated drunkenness were used as dependent variables; the HBSC period was used as an independent predictor of the bina-

Table 1. Sample structure for the study, by gender, age and period, Czech Republic, HBSC data 1994-2014.

\begin{tabular}{|c|c|c|c|c|c|c|c|}
\hline Gender & Age group & 1994 & 1998 & 2002 & 2006 & 2010 & 2014 \\
\hline Boys & $\begin{array}{l}11 \text { y.o. } \\
13 \text { y.o. } \\
15 \text { y.o. } \\
\text { Total boys }\end{array}$ & $\begin{array}{c}539 \\
644 \\
606 \\
1789\end{array}$ & $\begin{array}{c}586 \\
646 \\
607 \\
1839\end{array}$ & $\begin{array}{c}826 \\
780 \\
806 \\
2412\end{array}$ & $\begin{array}{c}765 \\
804 \\
842 \\
2411\end{array}$ & $\begin{array}{c}719 \\
669 \\
747 \\
2135\end{array}$ & $\begin{array}{c}738 \\
818 \\
852 \\
2408\end{array}$ \\
\hline Girls & $\begin{array}{l}11 \text { y.o. } \\
13 \text { y.o. } \\
15 \text { y.o. } \\
\text { Total girls }\end{array}$ & $\begin{array}{c}555 \\
646 \\
595 \\
1796\end{array}$ & $\begin{array}{c}598 \\
644 \\
622 \\
1864 \\
\end{array}$ & $\begin{array}{c}865 \\
881 \\
854 \\
2600\end{array}$ & $\begin{array}{c}744 \\
797 \\
823 \\
2364\end{array}$ & $\begin{array}{c}707 \\
787 \\
775 \\
2269\end{array}$ & $\begin{array}{c}836 \\
903 \\
908 \\
2647\end{array}$ \\
\hline Total & $\begin{array}{l}11 \text { y.o. } \\
13 \text { y.o. } \\
15 \text { y.o. } \\
\text { Total sample size }\end{array}$ & $\begin{array}{l}1094 \\
1290 \\
1201 \\
3585 \\
\end{array}$ & $\begin{array}{l}1184 \\
1290 \\
1229 \\
3703 \\
\end{array}$ & $\begin{array}{l}1691 \\
1661 \\
1660 \\
5012 \\
\end{array}$ & $\begin{array}{l}1509 \\
1601 \\
1665 \\
4775 \\
\end{array}$ & $\begin{array}{l}1426 \\
1456 \\
1522 \\
4404 \\
\end{array}$ & $\begin{array}{l}1574 \\
1721 \\
1760 \\
5055\end{array}$ \\
\hline
\end{tabular}

Table 2. Adolescent alcohol use prevalence estimates (\%), by gender, age and period, Czech Republic, HBSC (1994-2014).

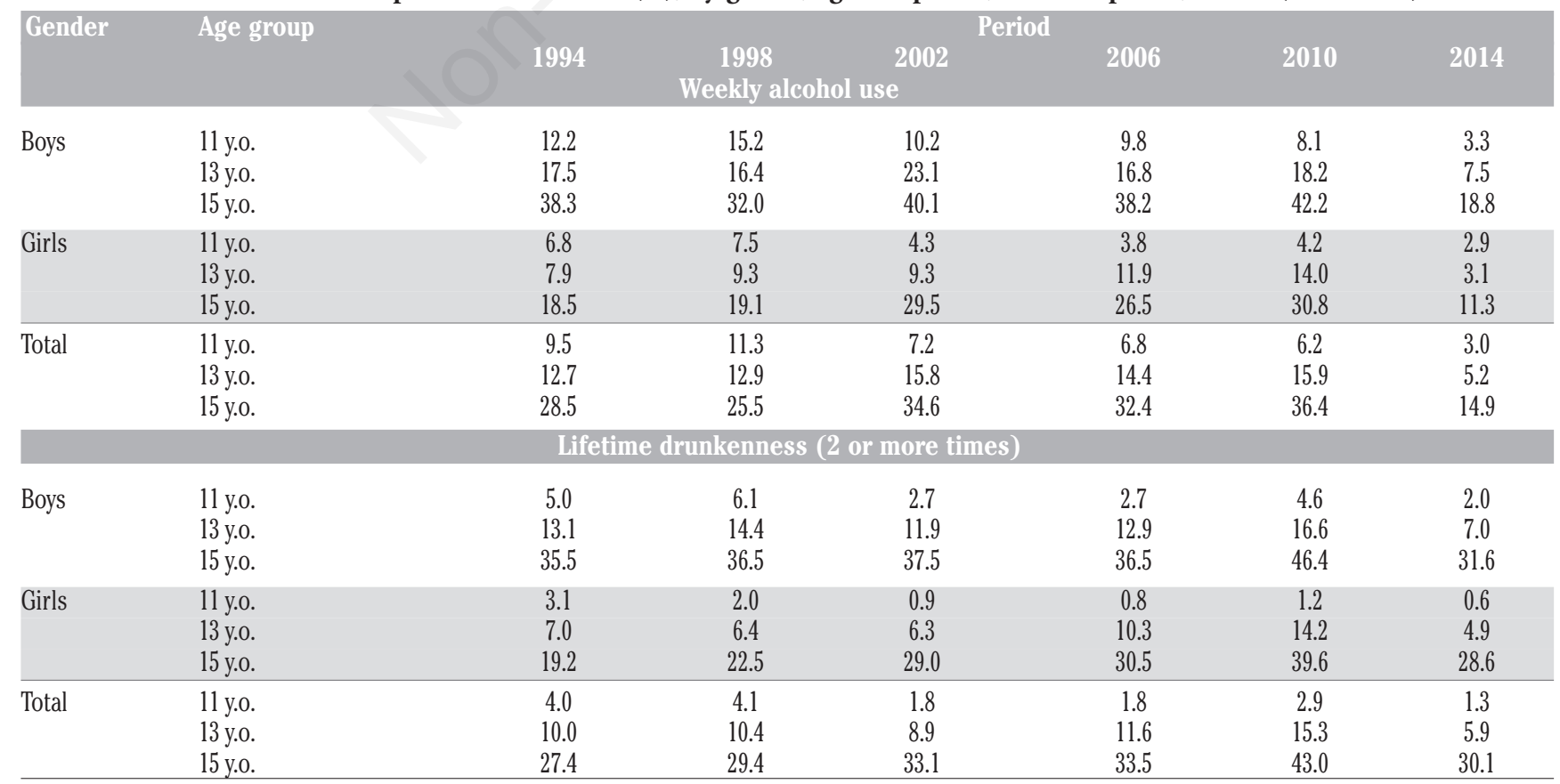


ry indicator. The regression models were split into two consecutive time-periods (1994-2010 and 2010-2014), and conducted separately for 13- and 15-year-old students - both for total prevalence and gender-specific trends. The results are presented in Tables 3 and 4.

The results of regression analyses generally confirmed previous findings from Figures 1 and 2. The prevalence of alcohol use among adolescents experienced significant changes in the Czech Republic during the period 1994-2014. At first, there was a gradual increase from 1994 to 2010, which was more pronounced among girls. However, there was a significant drop in this respect between years 2010 and 2014. This decline was significant across both genders and age groups surveyed in the study.
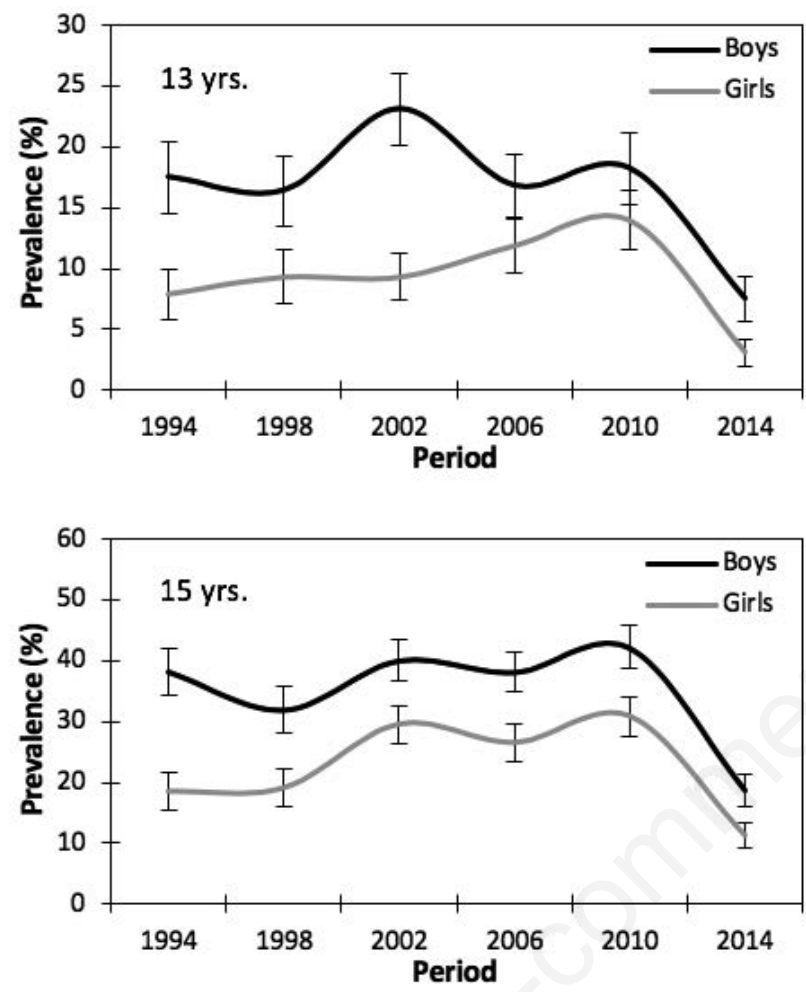

Figure 1. Trends in weekly alcohol use $(\%, 95 \% \mathrm{CI})$, by age and gender, Czech Republic, HBSC (1994-2014).

\section{Discussion and Conclusions}

The results of the study lead to a discussion in at least three interrelated aspects. First, it is essential to reflect the significant changes in temporal trends of alcohol use among the Czech adolescent population. The results of our analysis revealed a significant increasing trend of both adolescent weekly alcohol use and repeated drunkenness from 1994 to 2010, which was followed by a steep decrease in 2014, as compared to the previous HBSC round conducted in 2010 .

The results of our study confirm the significant changes in adolescent alcohol use provided by the recent ESPAD study. Studies
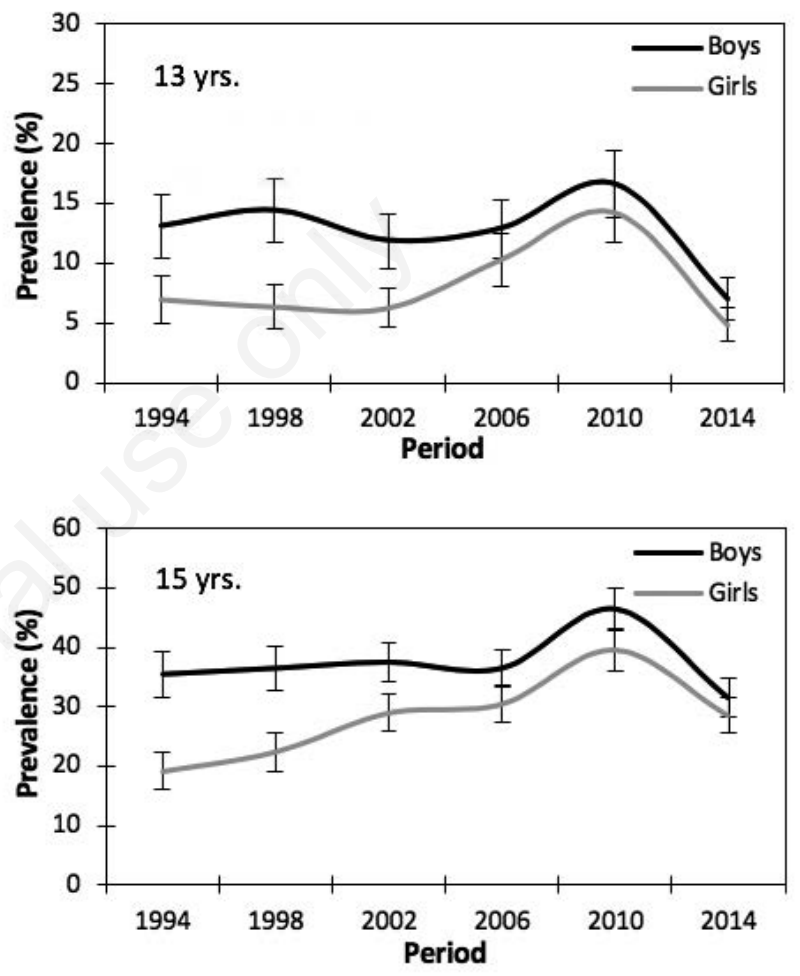

Figure 2. Trends in repeated lifetime drunkenness (\%, 95\% CI), by age and gender, Czech Republic, HBSC (1994-2014).

Table 3. Binary logistic regression, by gender and age. Dependent variable - weekly alcohol use (Yes = 1; No = 0), Czech Republic, HBSC (1994-2014).

\begin{tabular}{|c|c|c|c|c|c|c|c|}
\hline \multirow[t]{2}{*}{ Gender } & \multirow[t]{2}{*}{ Age group } & \multicolumn{3}{|c|}{ Model 1994-2010 } & \multicolumn{3}{|c|}{ Model 2010 vs. 2014} \\
\hline & & Independent ${ }^{\mathrm{a}}$ & Beta (SE) & Sig. & Independent ${ }^{\mathrm{b}}$ & Beta (SE) & Sig. \\
\hline \multirow[t]{4}{*}{ Boys } & \multirow[t]{2}{*}{13 y.o. } & Time period & $0.00(0.008)$ & 0.785 & 2014 & $-1.02(0.167)$ & $<0.001$ \\
\hline & & Constant & $-1.50(0.078)$ & $<0.001$ & Constant & $-1.50(0.100)$ & $<0.001$ \\
\hline & \multirow[t]{2}{*}{15 у.о. } & Time period & $0.01(0.006)$ & 0.018 & 2014 & $-1.15(0.115)$ & $<0.001$ \\
\hline & & Constant & $-0.60(0.064)$ & $<0.001$ & Constant & $-0.32(0.074)$ & $<0.001$ \\
\hline \multirow[t]{4}{*}{ Girls } & \multirow[t]{2}{*}{13 у. 0.} & Time period & $0.04(0.010)$ & $<0.001$ & 2014 & $-1.62(0.218)$ & $<0.001$ \\
\hline & & Constant & $-2.49(0.107)$ & $<0.001$ & Constant & $-1.82(0.103)$ & $<0.001$ \\
\hline & \multirow[t]{2}{*}{15 у. 0.} & Time period & $0.04(0.007)$ & $<0.001$ & 2014 & $-1.25(0.130)$ & $<0.001$ \\
\hline & & Constant & $-1.44(0.076)$ & $<0.001$ & Constant & $-0.81(0.078)$ & $<0.001$ \\
\hline \multirow[t]{4}{*}{ Total } & \multirow[t]{2}{*}{13 у.o. } & Time period & $0.02(0.006)$ & 0.009 & 2014 & $-1.25(0.130)$ & $<0.001$ \\
\hline & & Constant & $-1.91(0.062)$ & $<0.001$ & Constant & $-1.66(0.072)$ & $<0.001$ \\
\hline & \multirow[t]{2}{*}{15 y.o. } & Time period & $0.03(0.005)$ & $<0.001$ & 2014 & $-1.18(0.085)$ & $<0.001$ \\
\hline & & Constant & $-0.98(0.048)$ & $<0.001$ & Constant & $-0.56(0.053)$ & $<0.001$ \\
\hline
\end{tabular}

aTime period is a continuous variable representing number of years since the baseline period 1994. ${ }^{\mathrm{b}}$ Reference year $=2010$. 
conducted on the Czech ESPAD data revealed both the continuous increasing trend in adolescent last month binge drinking and alcohol intoxication, for the period of 1995-2011, and a sharp decline recorded in 2015 compared to $2011 .{ }^{18}$ Similarly to our study, the prior increase in alcohol use was more pronounced among girls, which led to converging the levels between genders. ${ }^{19}$ The subsequent drop in adolescent alcohol use during 2011 and 2015 was reported proportionally among both boys and girls. ${ }^{18,19}$

The general downward trend in adolescent alcohol use was documented also in other European countries, ${ }^{20}$ as well as among adolescents from the US, ${ }^{7}$ Canada $^{14,16}$ or Australia. ${ }^{9}$ Compared to the Czech Republic, the downward trend was not steep but gradual and long-term. Therefore, the case of the Czech adolescents seems to be rather specific and there is a need for closer discussion on the phenomena.

The second aspect is to discuss the factors that might to contribute to recent decline in alcohol use. The explanation lies in a rather complex mixture of several factors. In this respect, it is important to note that from 2010 no political measures have been introduced in the Czech Republic that would alter the availability of alcohol. Nor did any massive campaign take place that could significantly affect the attitudes of young people towards alcohol use. In a similar vein, there were no major public health interventions in substance use prevention, which could possibly outweigh the practice common in previous years. ${ }^{21}$

Specific explanation for the recent decline in alcohol use concerns the changing preferences of leisure activities among the contemporary Czech youth. ${ }^{22}$ Easy access to the Internet, and increasing availability of computers, tablets or smartphones leads to the situation, when young people spend hours on digital technologies. As documented by both the HBSC and ESPAD data, there was a gradual increase in total time spent on computer and use of e-media among adolescents across the European countries in the last decade, including Czechia. ${ }^{23,24}$ At the same time, these activities are more frequent during weekends and linked to leisure preferences and new lifestyle patterns of the contemporary youth.

The recent study by Chomynová and Kážmér ${ }^{22}$ (in review) provides empirical evidence of the changing preferences of leisure among the adolescent Czechs, particularly with respect to the significantly lowered frequency of going out with friends and peers during out-of-school time. Interestingly, the lowered frequency explained major part of recent decline in adolescent alcohol use (51-99\% of declines in the prevalence of alcohol intoxication and binge drinking between periods of 2011 and 2015), which is prob- ably also related to the spread of new digital technologies. However, while the total time "spent in a virtual space" among the Czech youth is growing, authors of this study are of the opinion that it would be yet premature to talk about replacing one form of risk behavior (alcohol use) with another (excessive use of digital technologies). Furthermore, it turns out that the unprecedented changes do not concern only alcohol but also the use of other substances, e.g. adolescent tobacco smoking and marijuana use. ${ }^{18,25,26}$ In this regard, results of both HBSC and ESPAD yielded congruent findings and confirmed the general decrease of substance use among Czech adolescents in the recent periods. For example, the current smoking prevalence rates among 15-year-old students, derived from the recent Czech HBSC surveys, dropped from $25.0 \%$ in 2010 to $13.3 \%$ in 2014 , proportionally in both genders. ${ }^{25}$ The last month prevalence of tobacco smoking dropped from $42.3 \%$ in 2011 to $29.9 \%$ in 2015 (the Czech ESPAD surveys). ${ }^{18}$ Similarly, the prevalence of lifetime marijuana use among 15 -yearold respondents, as reported by the HBSC, declined from $30.5 \%$ in 2010 to $23.1 \%$ in 2014 , as reported by the ESPAD from $42.3 \%$ in 2011 to $36.8 \%$ in 2015 (in the ESPAD, the prevalence of marijuana use and/or hashish together). ${ }^{18,26}$ Since the use of one type of a substance is usually correlated to the use of other substance(s), ${ }^{27}$ these findings point to rather general decrease of adolescent substance use. At the same time, these findings are concordant to the above-mentioned hypothesis on ongoing changes in leisure time preferences among the contemporary Czech youth, resulting in an overall decrease of substance use in this specific population group.

From the cross-European perspective, in Scandinavian countries, where a continuous decline in adolescent alcohol use since early 2000s was documented, broader social and political factors linked to an efficient policy measures are considered as possible underlying causes, including lower availability of alcohol beverages, better parental supervision over the children leisure activities, and the reduced opportunities for alcohol drinking, when young people go out for fun. ${ }^{28,29}$ Worldwide, socio-cultural factors and possible generational shift in health-related norms are discussed, as well. ${ }^{17,30}$ However, regarding the Czech adolescents, we consider these eventual factors rather secondary.

The third aspect is the narrowing gap in alcohol use between adolescent boys and girls. The phenomenon was discussed on the example of several developed countries of Europe and North America by the study of Kuntsche et al., ${ }^{31}$ applying the HBSC data from 1998 to 2006. The authors conclude that shrinking of gender inequalities in health-related behaviors is part of a more general

Table 4. Binary logistic regression, by gender and age. Dependent variable - repeated lifetime drunkenness $($ Yes $=1$; No = 0$)$, Czech Republic, HBSC (1994-2014).

\begin{tabular}{|c|c|c|c|c|c|c|c|}
\hline \multirow[t]{2}{*}{ Gender } & \multirow[t]{2}{*}{ Age group } & \multicolumn{3}{|c|}{ Model 1994-2010 } & \multicolumn{3}{|c|}{ Model 2010 vs. 2014} \\
\hline & & Independenta & Beta (SE) & Sig. & Independent ${ }^{\mathbf{b}}$ & Beta (SE) & Sig. \\
\hline \multirow[t]{4}{*}{ Boys } & \multirow[t]{2}{*}{13 y.o. } & Time period & $0.01(0.009)$ & 0.191 & 2014 & $-0.97(0.173)$ & $<0.001$ \\
\hline & & Constant & $-1.94(0.090)$ & $<0.001$ & Constant & $-1.61(0.105)$ & $<0.001$ \\
\hline & \multirow[t]{2}{*}{15 у.o. } & Time period & $0.02(0.006)$ & $<0.001$ & 2014 & $-0.63(0.104)$ & $<0.001$ \\
\hline & & Constant & $-0.67(0.065)$ & $<0.001$ & Constant & $-0.15(0.073)$ & 0.048 \\
\hline \multirow[t]{4}{*}{ Girls } & \multirow[t]{2}{*}{13 y.o. } & Time period & $0.06(0.011)$ & $<0.001$ & 2014 & $-1.17(0.186)$ & $<0.001$ \\
\hline & & Constant & $-2.88(0.123)$ & $<0.001$ & Constant & $-1.80(0.103)$ & $<0.001$ \\
\hline & \multirow[t]{2}{*}{15 y.o. } & Time period & $0.06(0.007)$ & $<0.001$ & 2014 & $-0.49(0.104)$ & $<0.001$ \\
\hline & & Constant & $-1.45(0.075)$ & $<0.001$ & Constant & $-0.42(0.074)$ & $<0.001$ \\
\hline \multirow[t]{4}{*}{ Total } & \multirow[t]{2}{*}{13 y.o. } & Time period & $0.03(0.007)$ & $<0.001$ & 2014 & $-1.06(0.126)$ & $<0.001$ \\
\hline & & Constant & $-2.33(0.072)$ & $<0.001$ & Constant & $-1.71(0.073)$ & $<0.001$ \\
\hline & \multirow[t]{2}{*}{15 y.o. } & Time period & $0.04(0.005)$ & $<0.001$ & 2014 & $-0.56(0.074)$ & $<0.001$ \\
\hline & & Constant & $-1.03(0.048)$ & $<0.001$ & Constant & $-0.28(0.052)$ & $<0.001$ \\
\hline
\end{tabular}

aTime period is a continuous variable representing number of years since the baseline period 1994 . ${ }^{\mathrm{b}}$ Reference year $=2010$ 
long-term process of convergence of gender-defined social roles.

Finally, it is important to assess the changing patterns of alcohol use among the adolescent Czechs, as compared to other countries participated in the HBSC study. Although the substantial decline recorded in 2014 is a positive trend for the national health policy, adolescent Czechs still remain above the HBSC average in both alcohol indicators. Compared to the Czech Republic, for the age of 15, the 2014 prevalence rates of weekly alcohol use across all HBSC countries was $9 \%$ for girls and $16 \%$ for boys, and rates of the repeated lifetime drunkenness were $20 \%$, and $24 \%$ respectively. ${ }^{32}$ Moreover, the adolescent Czechs have higher rates in both indicators compared to their immediate neighbors, i.e. adolescents from Germany, Poland, Slovakia and Austria. Therefore, the recent decline in adolescent alcohol use is not a reason for satisfaction. On the contrary, it is necessary to critically assess the national drug policy and look for more effective measures aimed at reducing alcohol consumption among the vulnerable groups of the Czech society.

Correspondence: Ladislav Csémy, National Institute of Mental Health, Topolová 748, 25067 Klecany, Czech Republic.

E-mail: ladislav.csemy@nudz.cz

Key words: alcohol use, adolescence, prevalence, trends, gender inequalities. Acknowledgements: The authors thank to Michal Kalman, PhD and the HBSC research team for provision of the Czech HBSC data for analyses.

Contributions: LC was responsible for the survey data collection and HBSC methodology compliance in Czechia. Both LK and LC performed statistical analyses, drafted the paper and contributed to literature review, and the final revision of the manuscript. Authors had full access to the survey data and read and approved the final manuscript.

Conflict of interest: the authors declare no potential conflict of interest.

Funding: This work was supported by the project of the Czech Science Foundation, grant number 18-17564S.

Received for publication: 11 October 2018.

Revision received: 27 December 2018.

Accepted for publication: 31 December 2018.

CC Copyright L. Kážmér and L. Csémy, 2019

Licensee PAGEPress, Italy

Journal of Public Health Research 2019;8:1493

doi:10.4081/jphr.2019.1493

This work is licensed under a Creative Commons Attribution NonCommercial 4.0 License (CC BY-NC 4.0). ety]. Psychiatrie 2012;16:210-16. [In Czech]

6. Bendtsen P, Damsgaard MT, Huckle T, et al. Adolescent alcohol use: a reflection of national drinking patterns and policy? Addiction 2014;109:1857-68.

7. Johnston LD, O'Malley PM, Miech RA, et al. Demographic subgroup trends among adolescents in the use of various licit and illicit drugs, 1975-2015 (Monitoring the Future Occasional Paper No. 86). Ann Arbor, MI: Institute for Social Research, University of Michigan; 2016.

8. ESPAD Group. ESPAD report 2015: results from the European school survey project on alcohol and other Drugs. Lisbon: European Monitoring Centre for Drugs and Drug Addiction; 2016

9. White V, Williams, T. Australian secondary school students' use of tobacco, alcohol, and over-the-counter and illicit substances in 2014. Melbourne: Cancer Council Victoria; 2016.

10. Williams CL, Toomey TL, McGovern PG, et al. Development, reliability, and validity of self-reported alcohol-use measures with young adolescents. J Child Adoles Subst 1995;4:17-40.

11. Brener ND, Billy JO, Grady WR. Assessment of factors affecting the validity of self-reported health-risk behavior among adolescents: evidence from the scientific literature. J Adolesc Health 2003;33:436-57.

12. Lintonen T, Ahlström S, Metso L. The reliability of self-reported drinking in adolescence. Alcohol Alcohol 2004;39:362-8.

13. Simons-Morton BG, Farhat T, ter Bogt TF, et al. Gender specific trends in alcohol use: cross-cultural comparisons from 1998 to 2006 in 24 countries and regions. Int J Public Health 2009;54:199-208.

14. Looze Md, Raaijmakers Q, Bogt TT, et al. Decreases in adolescent weekly alcohol use in Europe and North America: evidence from 28 countries from 2002 to 2010. Eur J Public Health 2015;25:69-72.

15. Brooks-Russell A, Farhat T, Haynie D, Simons-Morton B. Trends in substance use among 6th- to 10th-grade students from 1998 to 2010: findings from a national probability study. J Early Adolesc 2014;34:667-80.

16. Elgar FJ, Phillips N, Hammond N. Trends in alcohol and drug use among Canadian adolescents, 1990-2006. Can J Psychiatry 2011;56:243-7.

17. Pennay A, Livingston M, MacLean S. Young people are drinking less: it is time to find out why. Drug Alcohol Rev 2015;34:115-8.

18. Chomynová P, Csémy L, Mravčík V. Evropská školní studie o alkoholu a jiných drogách (ESPAD) 2015. Zaostřeno 2016;5:116.

19. Kážmér L, Orlíková B. [Temporal trends and risk factors of excessive alcohol consumption among Czech adolescents]. Adiktologie 2017;17:118-32. [In Czech]

20. Kraus L, Seitz NN, Piontek D, et al. Are the Are the Times A-Changin? Trends in adolescent substance use in Europe. Addiction 2018;113:1317-32.

21. Mravčík V, Chomynová P, Grohmannová K., et al. [Annual report on drug situation 2016 - Czech Republic]. Prague: Government of the Czech Republic; 2017. [In Czech]

22. Chomynová P, Kážmér L. Going out with friends as a mediator of recent decline in alcohol use in Czech adolescents. [In review].

23. Sigmundová D, Sigmund E, Bucksch J, et al. Trends in screen time behaviours in Czech schoolchildren between 2002 and 2014: HBSC study. Cent Eur J Public Health 2017;25:S15-20.

24. Spilkova J, Chomynova P, Csemy L. Predictors of excessive use of social media and excessive online gaming in Czech teenagers. J Behav Addic 2017;6:611-9.
5. Csémy L, Winkler P. [Alcohol in the Czech Republic: trends in consumption, health consequences and economic costs to soci- 
25. Salonna F, Kážmér L, Csémy L, et al. Trends in tobacco smoking among Czech school-aged children from 1994 to 2014. Cent Eur J Public Health 2017;25:S42-6.

26. Kážmér L, Csémy L, Ružbarská I, et al. Trends in lifetime cannabis use among Czech school-aged children from 2002 to 2014. Cent Eur J Public Health 2017;25:S47-50.

27. Kážmér L, Dzúrová D, Csémy L, Spilková J. Multiple health risk behaviour in Czech adolescents: family, school and geographic factors. Health Place 2014;29:18-25.

28. Pape H, Rossow I, Brunborg GS. Adolescents drink less: How, who and why? A review of the recent research literature. Drug Alcohol Rev 2018;37:S98-114.

29. Raitasalo K, Simonen J, Tigerstedt C, et al. What is going on in underage drinking? Reflections on Finnish European school survey project on alcohol and other drugs data 1999-2015.
Drug Alcohol Rev 2018;37:S76-84.

30. Pennay A, Holmes J, Törrönen J, et al. Researching the decline in adolescent drinking: The need for a global and generational approach. Drug Alcohol Rev 2018;37:S115-9.

31. Kuntsche E, Kuntsche S, Knibbe R, et al. Cultural and gender convergence in adolescent drunkenness: evidence from 23 European and North American countries. Arch Pediatr Adolesc Med 2011;165:152-8.

32. Inchley J, Currie D, Young T, et al., eds. Growing up unequal: gender and socioeconomic differences in young pe ple's health and well-being. Health Behaviour in School-aged Children (HBSC) study: international report from the 2013/2014 survey. Copenhagen: WHO Regional Office for Europe; 2016.Europe; 2016. 